Old Dominion University

ODU Digital Commons

Political Science \& Geography Faculty

Publications

Political Science \& Geography

2021

\title{
Nonprofit Capacity to Manage Hurricane-Pandemic Threat: Local and National Perspectives on Resilience During COVID-19
}

\author{
Nicole S. Hutton \\ Old Dominion University, nhuttons@odu.edu \\ Steven W. Mumford \\ Marina Saitgalina \\ Old Dominion University, msaitgal@odu.edu \\ Juita-Elena (Wie) Yusuf \\ Old Dominion University, jyusuf@odu.edu \\ Joshua G. Behr \\ Old Dominion University, jbehr@odu.edu
}

See next page for additional authors

Follow this and additional works at: https://digitalcommons.odu.edu/politicalscience_geography_pubs

Part of the Emergency and Disaster Management Commons, Nonprofit Administration and Management Commons, Political Science Commons, and the Strategic Management Policy Commons

\section{Original Publication Citation}

Hutton, N. S., Mumford, S. W., Saitgalina, M., Yusuf, J.-E. W., Behr, J. G., Diaz, R., \& Kiefer, J. J. (2021). Nonprofit capacity to manage hurricane-pandemic threat: Local and national perspectives on resilience during COVID-19. International Journal of Public Administration, 44(11-12), 984-993. https://doi.org/ 10.1080/01900692.2021.1922439

This Article is brought to you for free and open access by the Political Science \& Geography at ODU Digital Commons. It has been accepted for inclusion in Political Science \& Geography Faculty Publications by an authorized administrator of ODU Digital Commons. For more information, please contact digitalcommons@odu.edu. 


\section{Authors}

Nicole S. Hutton, Steven W. Mumford, Marina Saitgalina, Juita-Elena (Wie) Yusuf, Joshua G. Behr, Rafael Diaz, and John J. Kiefer 


\title{
Nonprofit Capacity to Manage Hurricane-Pandemic Threat:
}

\section{Local and National Perspectives on Resilience during COVID-19}

\author{
Nicole S. Hutton ${ }^{\mathrm{a}}$, Steven W. Mumford ${ }^{\mathrm{b} *}$, Marina Saitgalina ${ }^{\mathrm{c}}$, Juita-Elena (Wie) \\ Yusuf $^{\mathrm{c}}$, Joshua G. Behr ${ }^{\mathrm{d}}$, Rafael Diaz ${ }^{\mathrm{d}}, \&$ John J. Kiefer ${ }^{\mathrm{b}}$ \\ ${ }^{a}$ Department of Political Science and Geography, Old Dominion University, Norfolk, VA, \\ U.S.A.; ${ }^{b}$ Department of Political Science, University of New Orleans, New Orleans, LA, U.S.A.; \\ ${ }^{c}$ School of Public Service, Old Dominion University, Norfolk, VA, U.S.A.; ${ }^{d}$ Virginia Modeling, \\ Analysis and Simulation Center at Old Dominion University, Suffolk, VA, U.S.A. \\ *254 Milneburg Hall, University of New Orleans, 2000 Lakeshore Drive, New Orleans, LA \\ 70148, Tel: 504-280-3836, Fax: 504-280-3838, swmumfor@uno.edu.
}




\section{Nonprofit Capacity to Manage Hurricane-Pandemic Threat: Local and National Perspectives on Resilience during COVID-19}

This paper examines nonprofits' capacity for responding to simultaneous hurricane-pandemic threat, addressing: (1) strategies nonprofits use to deliver services during the COVID-19 pandemic, and (2) how natural hazards may affect nonprofit roles in emergency service delivery during a pandemic. Data come from a survey of New Orleans-based nonprofits demonstrating effects of pandemic on local nonprofit service delivery, and workshops with U.S. coastal community stakeholders exploring expectations for nonprofit roles in emergency operations nationwide. Nonprofits have applied resilient strategies including virtual operations, staff reductions, and funding diversification, but vulnerabilities remain. Findings guide a research agenda for building nonprofit and community resilience.

Keywords: nonprofit; resilience; COVID-19; hurricane; compound threat

\section{Introduction}

Responding to community needs in the event of a natural hazard during a pandemic - that is, a compound disaster event - presents challenges that are not well understood (Shultz et al., 2020). Natural hazards such as hurricanes and flooding may devastate the built environment and seriously disrupt economic and social normalcy. Nonprofits, often located in and serving the same communities devastated by the hazard, may likewise suffer damage to their facilities and experience disruptions to supply chains, an increase in staff absenteeism, and reduced revenue. Just as nonprofits help fill the gap in need among vulnerable populations during periods of normalcy, continuity in nonprofit service delivery throughout emergencies may be critical for community wellbeing, particularly during compound disasters. 
In hazardous settings, nonprofits may act on behalf of vulnerable populations to address needs that are otherwise unmet. In addition, public emergency management functions (i.e., disaster preparation, response, recovery, and mitigation) may be challenged by an increase in demand for critical services. Helping to meet this increased demand with truncated resources may over-tax nonprofits' ability to serve their communities. When the vigor of nonprofits is challenged, communities are less resilient and slower to recover (Behr \& Diaz, 2013, 2014; Mendel, 2003; Young, 2000; Jang et al., 2016).

This exploratory study identifies factors that may either promote or hinder nonprofit resilience during a compound hurricane-pandemic by asking: (1) What specific strategies have nonprofits used to deliver services during the COVID-19 pandemic? (2) How may a natural hazard affect nonprofit roles in emergency service delivery during a pandemic? This paper offers preliminary answers to the research questions through the lens of nonprofit resilience and adaptive capacity, and it proposes a framework and research agenda for prioritizing capacitybuilding interventions to enhance resilience.

Drawing upon a review of the literature related to nonprofit resilience, sustainability, and adaptive capacity, this paper posits a conceptual framework reflecting the intertwined nature of nonprofit and community resilience - defined as the organizational and collective capacities to withstand and recover from disruptive events - in public service provision during a compound disaster. Issues faced by nonprofits are identified through a practice-informed, two-pronged approach. First, data from a 2020 survey of New Orleans-based nonprofits are presented to explore how nonprofits are managing changes in service demand and resources stemming from the COVID-19 pandemic health crisis. Second, qualitative data from a series of workshops with disaster professionals and experts from across U.S. coastal communities are discussed to 
determine expectations associated with the nonprofit sector's involvement in planning for and responding to hurricane season in the midst of the COVID-19 pandemic.

\section{Nonprofit Capacities during Disaster}

Nonprofit delivery of both traditional and emergency services during a disaster (e.g., meal provision, public shelter support) requires resilience. In this paper, resilience is defined as the capacity to respond and adapt to adverse events (Hutton, 2018). Characteristics that promote nonprofit resilience are both internal and external (Rao \& Greve, 2018; McKinsey \& Company, 2001; Kimberlin et al., 2011; Valero et al., 2015), encompassing revenue, leadership, and partnerships (Minzner et al., 2014), and a focus on "processes, practices, and people" through financial management, strategic planning, and staff management (Shumate et al., 2017, p.155). Because nonprofits are embedded in their communities, nonprofit capacity influences community adaptive capacity, which consists of human and financial resources, embedded relationships and networks, strong leadership, and inclusive community participation in collective decision making (Chaskin, 2001; Maher et al., 2020). For example, a community’s volunteer and philanthropic capacities strengthen its ability to meet an increased demand for services, which is integral to the fulfilment of nonprofit roles in disaster.

The resources available to and required of nonprofits during emergencies also depend on the expectations of their government partners. Governments may influence which aspects of emergency management involve nonprofits and how they are integrated in disaster response (Hutton et al., 2016). In general, nonprofits perform three primary roles relative to government (Young, 2000): supplementary, complementary, and adversarial roles. Nonprofits perform supplementary roles by providing services similar to those delivered by government to help close gaps in needs, such as through facilitating response efforts and providing direct aid to vulnerable 
communities in the absence of public resources. Nonprofits also perform complementary roles by partnering with governments to establish trusting community relationships and increase service delivery in areas affected by the disaster. Adversarial roles situate nonprofits against governments through policy advocacy, which may address equity and justice concerns by drawing attention to emergent or overlooked needs that arise among vulnerable populations such as those susceptible to severe cases of COVID-19 (Clark et al., 2020; Wright \& Merritt, 2020).

Rao and Greve (2018) note that, while natural hazards often bring communities together through shared experience, disasters that involve contagious diseases weaken community social capital, collective resources, and capacity. For populations already distrusting of government, nonprofits' presence is even more necessary during a pandemic. Further, a pandemic may extend the return timeline for populations in need of services and increase staff and volunteer turnover (Shultz et al., 2020; Maher et al., 2020). Many nonprofits have a low propensity to plan for hazards because of high workloads and limited designated funding, instead relying on institutional knowledge and lessons learned from partners to absorb losses (Hutton et al., 2016). A nonprofit network with meaningful continuity of operations plans is an integral part of the resilience of communities faced with disruptions caused by compound events.

Based on the literature cited above, this paper suggests that a nonprofit's ability to withstand and recover from disruptions consists of four essential characteristics. First, like any organization designed to meet a need within a population, human and financial resources are essential to nonprofit operations. Second, embedded networks allow nonprofits to stay proximate to and familiar with community needs. Third, executive and board leadership provide vision and coordinated decision-making in support of capacity-building and enhanced resilience. Finally, 
community participation ensures a breadth of voices are heard and facilitates equitable decisions across stakeholder groups.

\section{Conceptual Framework}

The conceptual framework illustrated in Figure 1 was developed based on the literature to explain how nonprofit and community resilience interact during a hurricane-pandemic event to contribute to public emergency services through the three nonprofit roles defined by Young (2000): supplementary, complementary, and adversarial. Nonprofit resilience is the organization's ability to adapt or realign existing organizational capacities to fulfill service roles during an emergency and in the post-event, recovery environment (i.e., supporting relief, rehabilitation, reconstruction, and redevelopment efforts; Shumate et al., 2017). Community resilience is the ability of the community to moderate demand for services and provide volunteers to support nonprofits in fulfilling their roles during an emergency. Nonprofit and community resilience are enhanced by capacities enumerated in the framework, such as nonprofit operational capacity, mission orientation, and board leadership, as well as stakeholder participation and human and financial resources within the community (McKinsey \& Company, 2001; Drennan \& Morrissey, 2019; Simo \& Bies, 2007).

\section{[Insert Figure 1 Here]}

Adapting to changes in service demand is critical for nonprofit operations in areas that require frequent transition between normal and emergency operations, particularly those with crowded nonprofit sectors (Jenkins et al., 2015; Drennan \& Morrissey, 2019). Inventories of nonprofits in post-disaster settings show attrition among both emergent and pre-existing organizations, reflecting the establishment of new nonprofits to meet short-term needs associated with response and recovery as well as financial strain from resource reallocation and reduction. 
Reorganizing nonprofit organizations around shared goals allows increasingly crowded parts of the sector to realign so that critical services and partnerships established during a disaster can be sustained in the redistributed operating landscape (Hutton, 2018, 2019; Hutton et al., 2016).

\section{Materials and Methods}

This study applies the framework proposed in Figure 1 to identify facets of nonprofit adaptive capacity and resilience relevant to response to the COVID-19 pandemic and simultaneous hurricane evacuation and sheltering operations. Quantitative methods are used to assess how nonprofits located in the hurricane-prone region surrounding New Orleans, Louisiana, have responded to the COVID-19 pandemic. Qualitative methods are used to identify the needs of nonprofits located in coastal communities throughout the United States for addressing compound threats during hurricane season. This two-pronged approach offers perspectives on roles and resources that improve nonprofit capacities to manage compound hazards, both locally and nationally.

\section{Data}

Data are derived from two primary sources: a survey of nonprofits and a series of workshops with disaster professionals and experts. Both efforts were designated as not human subjects research by the respective Institutional Review Boards. First, between March 23 and May 13, 2020, researchers at the University of New Orleans collected online survey responses from a representative sampling of public charities across 13 parishes (counties) in the greater New Orleans metropolitan area. The survey queried nonprofits' service delivery strategies, existing capacities, and potential vulnerabilities in the early months of the COVID-19 pandemic in the United States. To derive the sample, a list of 501(c)3 public charities with addresses in the region was compiled from the Urban Institute's National Center of Charitable Statistics' (2020) 
cleaned version of the IRS Business Master Files (BMF) for December 2018. Following the Urban Institute's guidance, nonprofits that did not report at least $\$ 50,000$ in annual gross receipts over the prior two years were excluded from the sampling frame, as well as religious congregations and large outliers such as hospitals, clinics, universities, charter schools, and foundations.

Email contact information for the list of nonprofits (specifically for the Executive Director when available) was collected through a review of public websites and contact lists furnished by a community foundation sponsoring the research. The final sampling frame included 734 nonprofits with contact information. Of these, 370 responded to the survey, for a response rate of 50.4 percent. Respondents were representative of the population of public charities in the region in terms of parishes represented, mission type (e.g., human services, art and culture), and total annual revenues. Survey responses were analyzed using comparisons of means with $t$-tests of significance for continuous variables, and contingency tables with chisquare tests of significance for dichotomous variables.

Second, in May and June 2020, researchers at Old Dominion University and the University of South Florida convened six online workshops with 265 representatives of federal, state, and local agencies, nonprofit and volunteer organizations, and businesses. Workshop participants represented functions such as emergency management, public health, human services, and academic research, spanning across five federal agencies, 20 states, and 17 universities. The purpose of the workshops was to identify knowledge gaps, needs, and concerns related to the 2020 hurricane season during the COVID-19 pandemic. Workshop participants were uniquely positioned to identify critical issues associated with response to a hurricanepandemic event. 
Participants were recruited from researchers' professional and academic contacts in emergency management and public health through a convenience snowball sample. Participation in individual workshops ranged between 74 and 198 participants. Attendees were randomly assigned into concurrent breakout group sessions, which were each led by a moderator through the same semi-structured questionnaire. Breakout sessions were recorded and transcribed. Transcripts were manually analyzed to identify emergent themes and those associated with literature on nonprofit resilience, adaptive capacity, and emergency operations as integrated in Figure 1. Qualitative analysis of the discussion in these workshops revealed insights into the impact COVID-19 may have upon nonprofits' ability to support evacuation and sheltering needs. Quotes from workshop participants are included in this paper to illustrate the complex concerns of and demands on nonprofits to deliver critical services during a compound hazard.

\section{Results and Discussion}

The following section presents the results of the two-pronged study - from a survey of New Orleans nonprofits and workshops with disaster professionals and experts from U.S. coastal communities nationwide - with reference to the conceptual framework in Figure 1. We begin with brief discussion of the national and local (New Orleans) contexts in the early days of the pandemic in the United States, before presenting the local and national data.

\section{National Context: Coastal Communities and the Hurricane-Pandemic Threat}

In early spring 2020, COVID-19 began to make an impact in U.S. communities, quickly overwhelming health care infrastructure. However, these communities simultaneously faced the threat of other hazards (Quigley et al., 2020), such as tornadoes affecting the southern U.S. and catastrophic dam failures in Michigan. U.S. communities on the Gulf Coast and along the Atlantic coast had begun to anticipate the 2020 hurricane season lasting from June to November, 
forecasted as above-normal (National Oceanic and Atmospheric Administration, 2020). State and local governments in these at-risk areas have pre-existing plans for hurricane scenarios, but they generally do not account for a co-occurring pandemic (Andrews, 2020). It is within this particular context that emergency planners and other professionals supporting disaster functions began to undertake preparedness efforts and plan for how they would respond to a hurricane in the midst of a pandemic.

\section{Local Context: New Orleans Nonprofits Post-Katrina}

In normal times, the New Orleans region is challenged by inequities and poor outcomes in health, housing, employment, education, and justice (Data Center, 2018). Nonprofit services in the New Orleans region have varied with risk, economic fluctuations, and population decline. In the aftermath of Hurricane Katrina in 2005, New Orleans residents experienced an increase in needs during recovery (Kiefer et al., 2010). In response, new nonprofits formed, especially in health and human services, while others collaborated to expand their missions and take advantage of emerging funding opportunities.

Nonprofits with adaptive capacities were able to connect their expanded missions to the post-Katrina landscape (Jenkins et al., 2015; Simo \& Bies, 2007). Relationships with the federal government, and specifically the Federal Emergency Management Agency (FEMA), were crucial for nonprofits to fill funding gaps (complementary roles), expand post-disaster services (supplementary roles), and gain a seat at the table for community planning efforts (adversarial roles). Despite the increase in philanthropic dollars flowing to New Orleans, many smaller nonprofits struggled to survive. New Orleans health and human services nonprofits remained vulnerable far into the post-Katrina recovery, reporting modest median budgets and thin operating margins (Urban Institute, 2012). Through reorganization and realignment, some 
existing nonprofits were able to adapt and even thrive, and new entrepreneurial nonprofits emerged to meet the greater service demand.

The first positive case of COVID-19 in New Orleans emerged in early March 2020, and the city quickly became an early epicenter for the virus due in part to crowded Mardi Gras festivities. The pandemic and associated response efforts exacerbated existing challenges and inequities (Data Center, 2020). When the pandemic began, there were over 5,000 nonprofits with addresses in the 13-parish (county) region surrounding New Orleans that had specifically registered as 501(c)3 public charities, which are most likely to be directly involved in service provision in the wake of a disaster (Urban Institute National Center for Charitable Statistics, 2020). Among these public charities, close to one third were health and human services nonprofits, while the remainder focused on issues related to education, art and culture, and a range of other functions.

\section{Nonprofit Resilience to Pandemic in New Orleans}

The exploratory survey of New Orleans nonprofits operationalized "resilience" as those nonprofits able to continue providing direct services in the initial aftermath of the pandemic. Based on self-reported and open-ended explanations of services provided, a total of 172 respondents (46.4\%) met this criterion, half of which (50.6\%) were classified as "human services" organizations. The survey analysis compared the characteristics of these nonprofits to both the overall survey sample and nonprofits that were not providing direct services in immediate response to the pandemic. Table 1 shows these results.

[Insert Table 1 here]

Nearly all "direct service" nonprofits (85.9\%) were delivering some remote online services weeks into the disaster, which speaks to their strong adaptive capacity. Almost three- 
quarters $(72.9 \%)$ had already switched to remote telework, compared to just 42.5 percent of organizations not providing direct services. It is important to note, however, that direct service nonprofits, on average, tended to be larger and more formalized in terms of total annual revenues and full-time equivalent staff, and more likely to provide health insurance benefits and sick leave to full-time staff.

Direct services provided by nonprofits at the start of the pandemic most often included resources and referrals for direct provision of food, financial assistance (direct and/or through government benefits), medicine, and other basic needs to supplement or complement public services. In many cases, referral services were provided proactively over the phone or online as staff reached out to vulnerable client populations to assess needs. Nonprofits supplemented and complemented government services by providing remote tele-counseling and advising on issues such as health and nutrition, personal finances, legal support, and therapy, in addition to virtual learning opportunities, recreational classes, and artistic performances. Playing an adversarial role, nonprofits also advocated for policy change with local and state government on behalf of their clients and informed the public about the pandemic's impact and government response.

A small minority of direct service nonprofits continued to provide essential services in person, especially to medically fragile and otherwise vulnerable populations. These nonprofits depended on volunteer support and availability of personal protective equipment (PPE). Many nonprofits had to cancel, suspend, or delay programs that could not be adapted remotely, and focus on or develop new services that could. Even early in the pandemic, nonprofit representatives noticed a large increase in community demand for direct services. Limited preparation for the transition to telework strained nonprofit workers and partners, but these 
deficits in adaptive capacity may have been overcome through training and intentional collaboration (Akingbola, 2020).

Direct service providers did not differ significantly from their counterparts in terms of organizational age or having been founded prior to Hurricane Katrina. While service providers were significantly more likely to have a continuity of operations plan for disasters at the start of the pandemic, only 37.1 percent had such a plan. Open-ended survey responses suggested these plans were tailored to hurricanes and rarely addressed pandemic or compound threats.

Financially, direct service nonprofits exhibited few significant differences with other nonprofits in the region, and may have been slightly worse off that non-service providers. On average, direct service nonprofits had significantly less cash on hand and reserve funds, measured in terms of months of operating expenses covered. Service providers had an average of about 4.6 months of cash on hand and just two months' worth of reserves in the early weeks of the pandemic. Direct service organizations appear to operate on thin margins, which could threaten their sustainability.

While service providers were equally as likely as their counterparts to have cancelled fundraising events and lost earned income, they reported losing less of their budget on average due to event cancellations. This result may imply that direct service nonprofits are better able to diversify funding and adjust financially to short-term shock. Indeed, a majority of these nonprofits $(61.9 \%)$ anticipated and/or had already enacted staff reductions, including reduced hours and pay, furloughs, layoffs, and delayed hires. This immediate action to stabilize budgets aligns with resilient practices of both government and nonprofits during the pandemic (Maher et al., 2020). Staff reductions are an expected reaction to shifting contexts during a disaster, in 
addition to funding adjustments, volunteer recruitment, and planning to maintain service delivery (Akingbola, 2020).

Service providers were more likely than their counterparts to express interest in pursuing government funds in response to the pandemic, including federal Paycheck Protection Program (PPP) forgivable loans available to nonprofits through the Small Business Administration (SBA). Indeed, 77.8 percent of service providers sought government funding in response to the pandemic, compared to a still substantial 59.2 percent of other nonprofits. In fact, almost 33,000 of the regional nonprofit sector's jobs were retained for an additional two months in summer 2020, according to analysis of PPP data from the SBA (2020). Comparison to nonprofit employment estimates from the region provided by the federal Bureau of Labor Statistics (BLS, 2017) suggest that these saved jobs represent as many as three-fifths of total nonprofit jobs in the region. In addition to government funding, most nonprofits across the sample indicated a need for private philanthropic support in the form of general operating funds.

Finally, direct service nonprofits appear to have had greater social capital - in terms of connections to community funding networks and interest in collaboration - than their counterparts, possibly augmenting their resilience. Service providers were significantly more likely to participate in an annual regional virtual fundraising event, Give NOLA Day, and to be beneficiaries of a progressive funders' network of large and well-endowed national and regional foundations. Further highlighting their social ties, direct service nonprofits expressed greater interest in a new collaboration or merger in the near future, although only 15.0 percent did so.

\section{The Threat of Hurricane Season during COVID-19}

The qualitative findings of the six national workshops offer additional insights about the roles of nonprofits in responding to a compound threat as delineated in Figure 1. Workshop 
results complement findings from the New Orleans survey by providing perspectives from other geographic contexts and scales, including state and federal government. First, national workshop participants noted that staff and volunteers were experiencing signs of physical, mental, and emotional fatigue, raising concerns that the prolonged pandemic can lead to "COVID-19 fatigue" and burnout. As one participant stated, "Many of the same staff that help during hurricane season or in shelters are the same workers helping with COVID-19... They are tired physically and mentally." The risk of compassion fatigue was also recognized, with the implication that nonprofit staff and volunteers may be less willing to take on additional service roles (Burnett, Jr., 2017).

Second, responding to COVID-19 had impacted nonprofit resources beyond human capital. Financial resources and supplies were depleted, calling into question whether those resources would be available for a hurricane event. As noted by a participant, "funding is a huge issue... is always a struggle," and a major challenge has been the "lack of funding for organizations as this [COVID-19] drags on." Nonetheless, during the 2020 hurricane season, nonprofits were expected to fulfill not only their traditional roles in disaster response and recovery, but also expanded roles because of the socio-economic impacts of COVID-19. Participants expressed concerns about residents' abilities to prepare for hurricanes and evacuate. The pandemic negatively affected the economic security of many residents - a key factor in community resilience - due to reduced work hours and job loss (Montenovo et al., 2020; Coibion et al., 2020). Residents choosing to shelter at home or with family or friends would need assistance with sourcing and obtaining supplies. If residents were required to bring PPE with them to a shelter, nonprofits would need to connect them with supplies in advance. A participant also suggested nonprofits may be required to provide non-congregate shelters. At the 
same time, social networks were strained by fear and anxiety of virus transmission (Tandon, 2020). Human services nonprofits were expected to address these needs throughout the pandemic and prepare residents for a hurricane-pandemic threat, such as by "partner[ing] with nonprofit organizations and faith-based organizations that work with vulnerable populations to disseminate [preparedness] information."

COVID-19 posed challenges to typical planning and operation for evacuation and sheltering (Pei et al., 2020). Participants noted that government budget constraints and furloughs, layoffs, and hiring freezes reduced the availability of shelter staff (Auerbach et al., 2020). Yet sheltering during COVID-19 requires expanded facilities and transportation options (both congregate and non-congregate) to maintain social distancing, as well as additional space to allow for quarantine or isolation areas, staff with specialized skill sets for screening and managing symptomatic populations, and equipment and training for new cleaning protocols (Cowling \& Aiello, 2020; Fong et al., 2020). Participants also called for expanded wellbeing services for shelter staff and clients to address anxieties about virus transmission and increased domestic and substance abuse (Tandon, 2020; Lai et al., 2020; Shanafelt et al., 2020), alongside the trauma associated with natural hazards. Although some of these support services may be provided by the public or private sector, volunteers from and coordination with nonprofits would be necessary to inform and manage evacuees, especially those representing vulnerable populations.

Workshop participants noted the importance of nonprofit and community volunteers in supporting shelter operation, while recognizing that volunteer pools are affected by COVID-19 illness and risk of exposure (Clark et al., 2020). A workshop participant succinctly stated, "It is already difficult to get enough volunteers, and volunteer rates may be even lower this hurricane 
season due to COVID-19." Participants suggested that nonprofits supporting sheltering activities need to know what the shelters will look like and the specific roles they will fill with the COVID-19 precautions to assist with training and reassure their staff, volunteers, and target populations about shelters' safety.

In the event of a natural hazard, nonprofits may be leveraged to provide a refuge of last resort for those who choose not to evacuate and can no longer access public shelters, likely a higher proportion than usual during a pandemic due to fears of virus transmission. Nonprofits eligible for this use would need clear expectations. Whereas some counties intentionally manage shelters with social service agencies and the health department, others do not have strong information streams between nonprofits and emergency management, hampering nonprofit preparedness and overall community capacity to provide emergency services.

\section{Conclusion}

To illuminate the relevant aspects of nonprofit resilience, this study first asked what specific strategies nonprofits are using to deliver services during the COVID-19 pandemic. The exploratory survey data suggest a profile of the most resilient nonprofits responding to the early stages of the pandemic in New Orleans. These nonprofits exhibited adaptive capacity by immediately shifting services and internal work online and expanding their strategies and capacities to meet client populations' emergent needs. They demonstrated, on average, sufficient size and structure in terms of staffing levels, income, staff benefits, and information technology infrastructure to respond to the pandemic. However, their lean operating margins and general lack of disaster plans addressing pandemic or compound threat forced many to realign resources, especially by reducing personnel costs and seeking new funding streams with public and private funders. These findings are consistent with resilient aspects of nonprofits identified in Figure 1. 
They support a holistic portrayal of how nonprofit capacities intertwine to adapt to disaster by (1) sustaining and even expanding services to meet the increased community demand, (2) aligning strategies and resources to the evolving context, and (3) filling in gaps in government services.

Nonprofits are expected to exhibit continuity in service delivery in a shifting environment. Yet the uncertainty inherent to such environments may compromise the successful transition of nonprofits to post-event recovery. This uncertainty is further exacerbated by a pandemic. Workshop participants noted that, across the country, pandemic effects have manifested in reduced funding, strained budgets, and volunteer and supply shortages for evacuation activities. Many nonprofits in New Orleans exhibited resilience to the pandemic by using their adaptive capacity to change service delivery methods, reach out to emergent vulnerable populations, and adjust their funding streams accordingly. However, findings also reveal potential vulnerabilities in nonprofit resilience as a result of the COVID-19 pandemic, particularly related to financial and human resources and collaborations. Some private funders are responding with flexible operating grants and capacity-building opportunities for nonprofits (e.g., in disaster planning, financial diversification, collaboration), but it remains to be seen whether these efforts successfully build nonprofit - and subsequently community - resilience in the face of compound threats.

To explore the application of resilient strategies to a compound hazard, the second research question addressed how a natural hazard affects nonprofit roles in emergency service delivery during the COVID-19 pandemic. Not all realignments used by New Orleans' local nonprofits to address the pandemic will translate to operational capacity during a compound threat, but some could inform how emergency services like shelters operate. Transitioning 
nonprofit services online can maintain service provision to some populations during the pandemic, but not necessarily during a hurricane evacuation because of potential power outages. Nonetheless, the protocols implemented by in-person service providers during the pandemic could be applicable to shelters. National workshop participants stated that responding to a hurricane-pandemic threat will require recruiting new volunteers and partners, strengthening leadership, realigning strategies to fit an expanded mission, and enhancing external communication, all within the context of a potentially reduced resource base.

\section{Recommendations}

Compound hazards offer opportunities for nonprofits to support long-term risk reduction. The following recommendations are offered to guide communities - and especially public emergency management professionals - in leveraging nonprofit capacity to support compound hazard response and long-term disaster recovery:

- Nonprofits that expanded services, such as meal provision, during the pandemic might serve as a growing resource to emergency managers because of their increased reach.

- Volunteers and PPE for evacuation efforts could be mobilized through the available nonprofit resource base.

- Connecting with nonprofits for supplementary services during evacuation increases the likelihood that vulnerable populations are reached and continually served.

- Integration of nonprofits as complementary shelter staff and volunteers may reduce stresses associated with safety during the pandemic for populations that distrust government workers. 
- Specialized nonprofits, such as those in health, may be able to reach a larger audience during a compound threat through adversarial roles, direct service provision, and referrals made at shelters, and maintain these roles throughout the pandemic.

- The integration of non-traditional nonprofits, other than the Red Cross, into emergency planning could be a lasting lesson learned from compound hazard management.

- Technical skills for obtaining PPP loans and engaging with community foundations may improve capacity to garner federal disaster recovery grants, integrate with emergency governance, and maintain community trust.

A nonprofit resilience model, such as Figure 1, should be used for compound threat planning to overcome resource strain attributed to operating during a pandemic. The measures implemented by nonprofits in hazardous settings during the pandemic prepare them to fill gaps in government services. Further, collective action associated with consolidation and funding

flexibility are applicable to both types of hazards. As the pandemic progresses and natural hazards continue to occur, expansion and retraction of the nonprofit sector may solidify the most effective techniques and address crowding, such as through collaboration and service coordination with emergency management and health departments.

\section{Agenda for Future Research}

This paper's preliminary conclusions motivate a research agenda to further address our two research questions: (1) What specific strategies have nonprofits used to deliver services during the COVID-19 pandemic? (2) How may a natural hazard affect nonprofit roles in emergency service delivery during a pandemic? Building on our exploratory data, the first question can be answered more thoroughly through empirical tests of the conceptual framework proposed in Figure 1. Such analyses would examine capacity elements associated with resilience 
that best predict desirable outcomes, such as sustained or expanded services, in the face of compound threats. Our preliminary analysis suggests factors associated with flexible financial resources (e.g., multi-year operating grants), staff and volunteer safety and retention, compound disaster planning, and community networks and collaborations may be especially important for resilience.

In particular, future research is needed to test nonprofit resilience and sustainability following the unprecedentedly active 2020 hurricane season in the Gulf Coast, which caused evacuations throughout the state of Louisiana and elsewhere, strained an already compromised nonprofit infrastructure, and engaged national emergency management systems while the threat of COVID-19 was present. A 2021 follow-up survey of nonprofits in New Orleans is underway. Likewise, comparable data from other regions and localities would enhance generalizability of results and may differ substantially depending on the extent of government involvement in each jurisdiction. In addition, organization and community case studies from a variety of subsectors and locales would promote transfer of findings to nonprofit practitioners. In this way, an evidence base for building nonprofit resilience and strengthening service delivery during compound events can be established.

\section{Acknowledgements}

Funding for this research was provided by the National Science Foundation-funded Social Science Extreme Events Research (SSEER) Network and the CONVERGE facility at the Natural Hazards Center at the University of Colorado Boulder (NSF Award \#1841338), and the Greater New Orleans Foundation.

\section{Declaration of Interest}


Authors have no known financial benefit or conflict of interest from the direct applications of this research.

\section{Data Availability Statement}

Some of the data used during the study are available online in accordance with funder and partner data retention and sharing policies. Data from the Converge COVID-19 Working Group can be found online (https://sites.wp.odu.edu/hurricane-pandemic/). 


\section{References}

Akingbola, K. (2020). COVID-19: The prospects for nonprofit Human Resource Management. Canadian Journal of Nonprofit and Social Economy Research, 11(1), 16-20.

Andrews, R. G. (2020, May 9). What happens if a 'big one' strikes during the pandemic? The Atlantic. https://www.theatlantic.com/science/archive/2020/05/hurricane-earthquakewildfire-tornado-disaster-pandemic/611455/

Auerbach, A., Gale, B., Lutz, B., \& Sheiner, L. (2020). Fiscal effects of COVID-19. Paper presented at the Brookings Papers on Economic Activity. https://www.brookings.edu/bpea-articles/fiscal-effects-of-covid-19/

Behr, J. G., \& Diaz, R. (2013). Disparate health implications stemming from the propensity of elderly and medically fragile populations to shelter in place during severe storm events. Journal of Public Health Management and Practice, 19, S55-S62.

Behr, J. G., \& Diaz, R. (2014). Hurricane preparedness: Community vulnerability and medically fragile populations. The Virginia News Letter, 90(3).

Bureau of Labor Statistics [BLS]. (2017). Business employment dynamics: Research data on the nonprofit sector. https://www.bls.gov/bdm/nonprofits/nonprofits.htm

Burnett, Jr., H. J. (2017). Revisiting the compassion fatigue, burnout, compassion satisfaction, and resilience connection among CISM responders. SAGE Open, 7(3), 1-10. doi: $10.1177 / 2158244017730857$

Clark, A., Jit, M., Warren-Gash, C., Guthrie, B., Wang, H.H., Mercer, S.W., Sanderson, C., McKee, M., Troeger, C., Ong, K.L. and Checchi, F. (2020). Global, regional, and national estimates of the population at increased risk of severe COVID-19 due to underlying health conditions in 2020: A modelling study. The Lancet Global Health, 8(8), e1003-e1017.

Chaskin, R. J. (2001). Building community capacity: A definitional framework and case studies from a comprehensive community initiative. Urban Affairs Review, 36(3), 291-323.

Coibion, O., Gorodnichenko, Y. and Weber, M. (2020). Labor markets during the COVID-19 crisis: A preliminary view (No. w27017). National Bureau of Economic Research.

Cowling, B. J., \& Aiello, A. E. (2020). Public health measures to slow community spread of coronavirus disease 2019. The Journal of Infectious Diseases, 221(11), 1749-1751.

Data Center. (2018). The New Orleans Prosperity Index: Tricentennial edition. Data Center.

Data Center. (2020). Monitoring the COVID-19 pandemic in New Orleans and Louisiana. https://www.datacenterresearch.org/covid-19-data-and-information/covid-19-data/ 
Drennan, L., \& Morrissey, L. (2019). Resilience policy in practice-Surveying the role of community based organisations in local disaster management. Local Government Studies, 45(3), 328-349.

Fong, M. W., Gao, H., Wong, J. Y., Xiao, J., Shiu, E. Y., Ryu, S., \& Cowling, B. J. (2020). Nonpharmaceutical measures for pandemic influenza in nonhealthcare settings - Social distancing measures. Emerging Infectious Diseases, 26(5), 976-984.

Hutton, N.S., Tobin, G.A. \& Whiteford, L.M. (2016). Modeling nonprofit resilience in long-term recovery in Christchurch, New Zealand. The Professional Geographer, 68(4), 603-612.

Hutton, N.S. (2018). Sustaining resilience: Modeling nonprofit collaboration in recovery. The Professional Geographer, 70(4), 655-665.

Hutton, N.S. (2019). Institutionalizing nonprofit influences post-disaster. In Emerging Voices in Natural Hazards Research (pp. 251-284), Butterworth-Heinemann.

Jang, H. S., Feiock, R. C., \& Saitgalina, M. (2016). Institutional collective action issues in nonprofit self-organized collaboration. Administration \& Society, 48(2), 163-189.

Jenkins, P., Lambeth, T., Mosby, K. \& Van Brown, B. (2015). Local nonprofit organizations in a post-Katrina landscape: Help in a context of recovery. American Behavioral Scientist, 59(10), 1263-1277.

Kiefer, J. J., Jenkins, P. J., \& Laska, S. (2010). Attending to the forgotten: The elderly, collaborative practice, and evacuation. In Strategic Collaboration in Public and Nonprofit Administration: A Practice-based Approach to Solving Shared Problems (pp. 99-122), Taylor \& Francis CRC Press.

Kimberlin, S. E., Schwartz, S. L., \& Austin, M. J. (2011). Growth and resilience of pioneering nonprofit human service organizations: A cross-case analysis of organizational histories. Journal of Evidence-based Social Work, 8(1-2), 4-28.

Lai, J., Ma, S., Wang, Y., Cai, Z., Hu, J., Wei, N., Wu, J., Du, H., Chen, T., Li, R., Tan, H., Kang, L., Yao, L. Huang, M., Wang, H., Wang, G., Liu, Z., and Hu, S. (2020). Factors associated with mental health outcomes among health care workers exposed to coronavirus disease 2019. JAMA Network Open, 3(3), e203976-e203976.

Maher, C.S., Hoang, T. and Hindery, A. (2020). Fiscal responses to COVID-19: Evidence from local governments and nonprofits. Public Administration Review, 80(4), 644-650.

McKinsey \& Company (2001). Effective capacity building in nonprofit organizations. Venture Philanthropy Partners.

Mendel, S. C. (2003). The ecology of games between public policy and private action: Nonprofit community organizations as bridging and mediating institutions. Nonprofit Management \& Leadership, 13(3), 229-236. 
Minzner, A., Klerman, J. A., Markovitz, C. E., \& Fink, B. (2014). The impact of capacitybuilding programs on nonprofits: A random assignment evaluation. Nonprofit and Voluntary Sector Quarterly, 43(3), 547-569.

Montenovo, L., Jiang, X., Rojas, F.L., Schmutte, I.M., Simon, K.I., Weinberg, B.A. and Wing, C. (2020). Determinants of disparities in covid-19 job losses (No. w27132). National Bureau of Economic Research.

National Oceanic and Atmospheric Administration. (2020). Busy Atlantic hurricane season predicted for 2020 [Press release]. https://www.noaa.gov/media-release/busy-atlantichurricane-season-predicted-for-2020

Pei, S., Dahl, K. A., Yamana, T. K., Licker, R., \& Shaman, J. (2020). Compound risks of hurricane evacuation amid the COVID-19 pandemic in the United States. medRxiv.

Quigley, M. C., Attanayake, J., King, A., \& Prideaux, F. (2020). A multi-hazards earth science perspective on the COVID-19 pandemic: The potential for concurrent and cascading crises. Environment Systems and Decisions. doi: https://doi.org/10.1007/s10669-020$\underline{09772-1}$

Rao, H., \& Greve, H. R. (2018). Disasters and community resilience: Spanish flu and the formation of retail cooperatives in Norway. Academy of Management Journal, 61(1), $5-25$.

Shanafelt, T., Ripp, J., \& Trockel, M. (2020). Understanding and addressing sources of anxiety among health care professionals during the COVID-19 pandemic. JAMA, 323(21), 21332134. doi:10.1001/jama.2020.5893

Shultz, J. M., Kossin, J. P., Hertelendy, A., Burkle, F., Fugate, C., Sherman, R., Bakalar, J., Berg, K., Maggioni, A., Espinel, Z., Sands, D., LaRocque, R., Salas, R., and Galea, S. (2020). Mitigating the twin threats of climate-driven Atlantic hurricanes and COVID-19 transmission. Disaster Medicine and Public Health Preparedness, 1-10. doi:10.1017/dmp.2020.243

Shumate, M., Cooper, K. R., Pilny, A., \& Pena-y-lillo, M. (2017). The nonprofit capacities instrument. Nonprofit Management and Leadership, 28(2), 155-174.

Simo, G., \& Bies, A.L. (2007). The role of nonprofits in disaster response: An expanded model of cross-sector collaboration. Public Administration Review, 67, 125-142.

Small Business Association [SBA]. (2020). SBA Paycheck Protection Program Load Level Data. https://home.treasury.gov/policy-issues/cares-act/assistance-for-small-businesses/sbapaycheck-protection-program-loan-level-data

Tandon, R. (2020). COVID-19 and mental health: Preserving humanity, maintaining sanity, and promoting health. Asian Journal of Psychiatry. doi: 10.1016/j.ajp.2020.102256 
Urban Institute. (2012). Profile of nonprofit organizations in the greater New Orleans metropolitan area. Urban Institute.

Urban Institute National Center for Charitable Statistics. (2020). Internal Revenue Service, Exempt Organizations Business Master File 2020. https://nccs-data.urban.org/data

Valero, J. N., Jung, K., \& Andrew, S. A. (2015). Does transformational leadership build resilient public and nonprofit organizations? Disaster Prevention and Management, 24(1), 4-20.

Wright, J.E., \& Merritt, C.C. (2020). Social equity and COVID-19: The case of African Americans. Public Administration Review, 80(5), 820-826.

Young, R. D. (2000). Alternative models of government-nonprofit sector relations: Theoretical and international perspectives. Nonprofit and Voluntary Sector Quarterly, 29, 149-72. 


\section{Table 1}

Characteristics of New Orleans Nonprofits by Whether They Self-Reported Providing Direct Services in Immediate Response to Pandemic

\begin{tabular}{|c|c|c|c|}
\hline Characteristic & $\begin{array}{c}\text { Overall } M \text { or } \% \\
\quad(n=370)\end{array}$ & $\begin{array}{l}\text { Direct service } \\
\text { provider } M \text { or } \% \\
\quad(n=172)\end{array}$ & $\begin{array}{c}\text { Non-service } \\
\text { provider } M \text { or } \% \\
\quad(n=174)\end{array}$ \\
\hline \multicolumn{4}{|l|}{ Organizational Characteristics } \\
\hline Total annual revenues (2017) & $\$ 1,892,183$ & $\$ 3,143,783$ & $\$ 696,832^{*}$ \\
\hline \# of full-time equivalent staff & 19.8 & 34.1 & $6.7 *$ \\
\hline Age in years & 23.7 & 23.2 & 23.8 \\
\hline Human services mission & $40.9 \%$ & $50.6 \%$ & $30.2 \% *$ \\
\hline \multicolumn{4}{|l|}{ Operations } \\
\hline Provide remote services & $40.4 \%$ & $85.9 \%$ & $0.0 \% *$ \\
\hline Switched to telework & $57.6 \%$ & $72.9 \%$ & $42.5 \% *$ \\
\hline Provide staff health benefits & $60.4 \%$ & $73.7 \%$ & $46.0 \% *$ \\
\hline $\begin{array}{l}\text { Have continuity of operations } \\
\text { plan }\end{array}$ & $29.7 \%$ & $37.1 \%$ & $21.4 \% *$ \\
\hline \multicolumn{4}{|l|}{ Finances } \\
\hline \# of months cash on hand & 5.4 & 4.6 & $6.2 *$ \\
\hline \# of months reserve funds & 2.8 & 2.0 & 3.6 \\
\hline$\%$ event revenues lost & 18.3 & 14.8 & $22.4^{*}$ \\
\hline Plan to reduce staffing & $60.9 \%$ & $61.9 \%$ & $60.1 \%$ \\
\hline \multicolumn{4}{|l|}{ Funding Relationships } \\
\hline $\begin{array}{l}\text { Plan to pursue government } \\
\text { funds or loan (e.g., PPP) }\end{array}$ & $68.6 \%$ & $77.8 \%$ & $59.2 \% *$ \\
\hline Participate in Give NOLA Day & $64.0 \%$ & $73.8 \%$ & $54.6 \% *$ \\
\hline Grantee of funder network & $25.7 \%$ & $39.5 \%$ & $13.2 \% *$ \\
\hline
\end{tabular}

$* \mathrm{p}<.05$. 
Figure 1. Nonprofit and community resilience during hurricane-pandemic threat

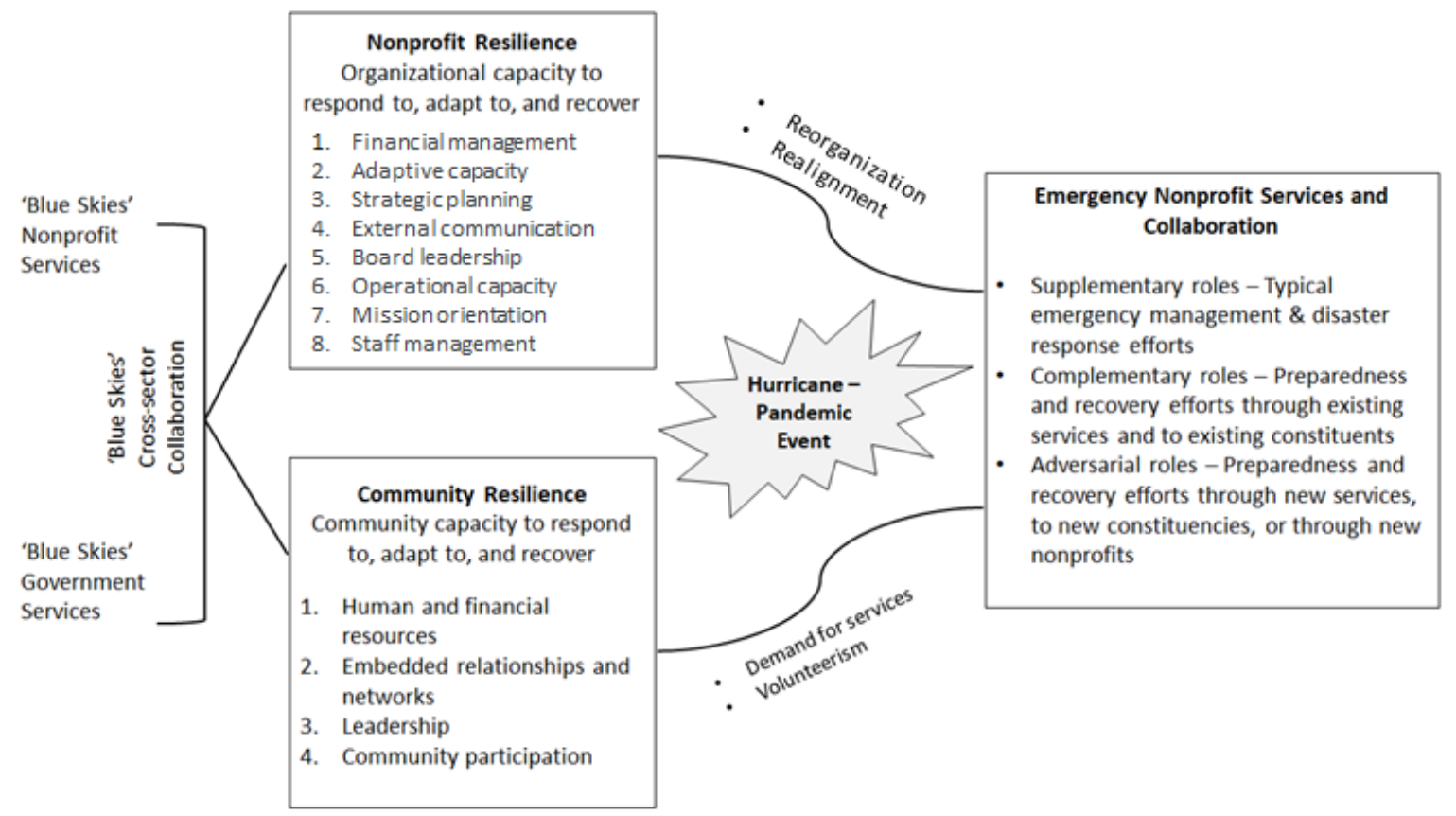

